\title{
New Compounds from Euphorbia helioscopia and Absolute Configuration Determination by Computational Methods
}

\author{
Jiangbo He, ${ }^{\dagger, \S, a}$ Hua-Jie Zhu, ${ }^{\dagger, a}$ Gui-Fen Luo, ${ }^{\dagger}$ Guang-Ming Liu, ${ }^{\S}$ Hao Chen,,${ }^{\ddagger}$ Yan Li, ${ }^{\dagger}$ Shaopeng Chen,${ }^{\ddagger}$ Xin Lu, ${ }^{\ddagger}$ \\ Guochun Zhou, ${ }^{\ddagger}$ and Yong-Xian Cheng ${ }^{\dagger, *}$
}

${ }^{\dagger}$ State Key Laboratory of Phytochemistry and Plant Resources in West China, Kunming Institute of Botany, Chinese Academy of Sciences, Kunming 650204, China. ${ }^{*}$ E-mail: yxcheng@mail.kib.ac.cn

${ }^{\ddagger}$ Guangzhou Institute of Biomedicine and Health, Chinese Academy of Sciences, Guangzhou 510530, China

${ }^{\S}$ College of Pharmaceutical Sciences, Dali University, Dali 671002, China

Received May 22, 2010, Accepted June 14, 2010

\begin{abstract}
The whole plant of Euphorbia helioscopia is an important traditional Chinese medicine. Fom its BuOH soluble extract, one new lactam (1), three new terpenoids (2-4) including a new naturally occurring compound, and three known compounds were isolated. Their structures were identified by spectroscopic evidences. In particular, the absolute configurations of side chain of compounds $\mathbf{1}$ and $\mathbf{2}$ were determined using computational methods.
\end{abstract}

Key Words: Euphorbia helioscopia, Euphorbiaceae, Lactam, Terpenoids, Quantum calculations

\section{Introduction}

The plants of the genus Euphorbia (Euphorbiaceae) have been extensively investigated and considered to be a rich source of biologically active compounds. ${ }^{1}$ E. helioscopia $\mathrm{L}$. is a traditional Chinese medicine widely distributed in China and has been used for the treatment of malaria, bacillary dysentery, and osteomyelitis. ${ }^{2}$ Previous reports on this plant mainly focused on diterpenoids, and up to now, almost 40 diterpenoids have been isolated. ${ }^{3-9}$ During our investigation on E. helioscopia, seven compounds were isolated, 4 of which were new ones (Figure 1). Herein, we describe their isolation and structure elucidation.

\section{Results and Discussion}

Compound 1 was determined to be $\mathrm{C}_{7} \mathrm{H}_{9} \mathrm{NO}_{4}$ by its HRESIMS. The ${ }^{13} \mathrm{C}$ NMR spectrum exhibited one methyl, one oxy- genated methylene, one oxygenated methine, two carbonyl groups, and two quaternary olefinic carbons. Two signals at $\delta$ 4.62 and $\delta 3.67 / 3.63$ in the ${ }^{1} \mathrm{H}$ NMR spectrum corresponded to $\mathrm{H}-6$ and H-7. Due to the scarcity of ${ }^{1} \mathrm{H}-{ }^{1} \mathrm{H}$ correlations, the structure of $\mathbf{1}$ was mainly assembled by HMBC correlations. The HMBC observations of H-8/C-5, C-4 and C-3, H-6/C-4, $\mathrm{C}-3, \mathrm{C}-2$ and $\mathrm{C}-7, \mathrm{H}-7 / \mathrm{C}-3$ and $\mathrm{C}-6$ deduced the partial structure of 1 to be $\mathrm{C}-2$ to $\mathrm{C}-8$. Besides two carbonyls, one double bond, one additional degree of unsaturation of 1 requires a ring constructed by $\mathrm{C}-2$ and C-5 via $\mathrm{NH}$ group. The absolute stereochemistry of $\mathbf{1}$ was assigned by quantum calculations. For $(R)$ isomer, its $\operatorname{det}(\mathrm{D})$ of matrix was predicted as -10.8 , the recorded optical rotation (OR) was -21.5 . The $\mathrm{k}_{0}$ for $\mathbf{1}$ was 2.0 , the predicted $\mathrm{k}_{0}$ was positive for chiral secondary alcohol. These exhibited that the absolute configuration at C- 6 of $\mathbf{1}$ is $R$. This conclusion was further confirmed using DFT methods. ${ }^{10}$ For example, $S$-isomer was used in OR computations in the gas phase, the

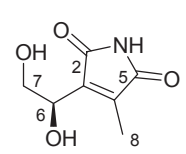

1

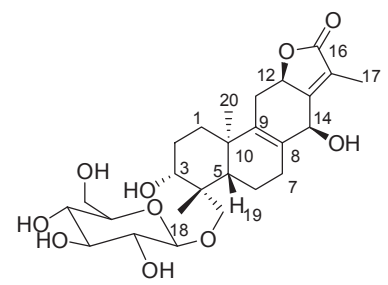

3

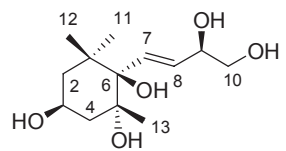

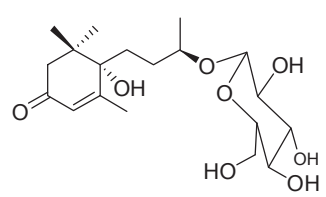

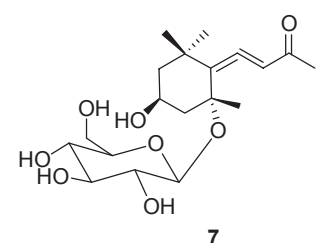

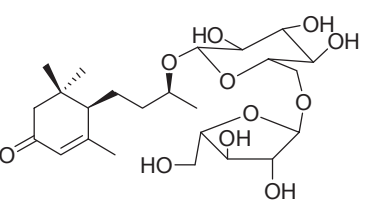

5

Figure 1. The structures of compounds 1-7.

${ }^{\mathrm{a}}$ These authors contributed equally to this paper. 
Table 1. NMR data for $\mathbf{1}^{a}$ and $\mathbf{2}^{a}$

\begin{tabular}{|c|c|c|c|c|}
\hline \multirow{2}{*}{ No - } & \multicolumn{2}{|c|}{1} & \multicolumn{2}{|c|}{2} \\
\hline & ${ }^{13} \mathrm{C}^{b}$ & ${ }^{1} \mathrm{H}^{c}$ & ${ }^{13} C^{b}$ & ${ }^{1} \mathrm{H}^{c}$ \\
\hline 1 & & & 40.6 & \\
\hline 2 & 173.7 & & 46.3 & $\begin{array}{l}1.64(\mathrm{t}, 12.1) \\
1.44(\mathrm{ddd}, 12.1,4.1,1.8)\end{array}$ \\
\hline 3 & 140.2 & & 65.2 & $4.04(\mathrm{~m})$ \\
\hline 4 & 141.9 & & 45.7 & $1.75(\mathrm{~m})$ \\
\hline 5 & 174.4 & & 77.8 & \\
\hline 6 & 68.6 & 4.62 (t-like) & 79.1 & \\
\hline 7 & 65.6 & $\begin{array}{l}3.67(\mathrm{dd}, 11.6,4.8) \\
3.63(\mathrm{dd}, 11.6,6.0)\end{array}$ & 133.7 & $6.17(\mathrm{dd}, 15.6,1.2)$ \\
\hline 8 & 8.9 & $2.00(\mathrm{~s})$ & 131.5 & $5.74(\mathrm{dd}, 15.6,6.0)$ \\
\hline 9 & & & 74.6 & $4.21(\mathrm{~m})$ \\
\hline 10 & & & 67.7 & $\begin{array}{l}3.51(\mathrm{dd}, 11.2,4.5) \\
3.48(\mathrm{dd}, 11.2,7.2)\end{array}$ \\
\hline 11 & & & 26.2 & $1.20(\mathrm{~s})$ \\
\hline 12 & & & 27.5 & $0.83(\mathrm{~s})$ \\
\hline 13 & & & 27.2 & $1.13(\mathrm{~s})$ \\
\hline
\end{tabular}

${ }^{a}$ In $\mathrm{CD}_{3} \mathrm{OD} ;{ }^{b}$ measured at $100 \mathrm{MHz} ;{ }^{c}$ measured at $400 \mathrm{MHz}$.

OR value was +81.2 without the consideration of water in solvent involved in the 1,2-diol structures. Therefore, the structure of 1 was identified (R)-3-(1,2-dihydroxyethyl)-4-methyl-1Hpyrrole-2,5-dione, namely heliolactam.

The molecular formula of 2 was determined as $\mathrm{C}_{13} \mathrm{H}_{24} \mathrm{O}_{5}$ by its HRESIMS. The ${ }^{13} \mathrm{C}$ NMR data (Table 1) showed three methyl, three methylene, four methine (including two olefinic ones), and three quaternary carbons, suggesting $\mathbf{2}$ to be a megastigmane-type norsesquiterpenoid and the planar structure resembling the aglycone of kowiionoside. ${ }^{11}$ The only difference was that $\mathrm{C}-10$ of 2 was oxygenated which resulted in a downfield shift of C-10 at $\delta 67.7$. The relative stereochemistry of 2 was determined by ROESY observations (Figure 2). ROESY correlations of $\mathrm{H}-11 / \mathrm{H}-3$ and $\mathrm{H}-7$ implied that $\mathrm{OH}-3$ and $\mathrm{OH}-6$ are both $\beta$. NOE enhancements of $\mathrm{H}-4, \mathrm{H}-7$, and $\mathrm{H}-8$ in combination of the absence of that for H-3 when irradiating H-13 indicated that $\mathrm{OH}-5$ is $\alpha$-form. The trans-relationship of double bond was assigned according to the coupling constant of $\mathrm{H}-7$ $(J=15.6 \mathrm{~Hz})$. The absolute configuration of C-9 was determined by quantum calculations. The OR values were calculated using DFT methods. ${ }^{10}$ Stable conformations were searched and the low energy conformations were optimized at the B3LYP/6-31G (d) level. ${ }^{12}$ The conformations with relative energy from $0-2.5$ $\mathrm{kcal} / \mathrm{mol}$ were used in OR computations at the b3LYP/augccpVDZ level. The computed OR value for $S$-configuration at C-9 of 2 was +113 in the gas phase. The experimental OR value was -32.8 . The two magnitudes had big differences and the OR signs were reversed. This exhibited that the stereogenic center is not $S$-configuration. OR computations for $\mathbf{2}$ with $(R)$-configuration at C-9 were performed using the same method as above. The calculated OR value was -12.0 in the gas phase. This value is close to the experimental -32.8 , and the OR sign

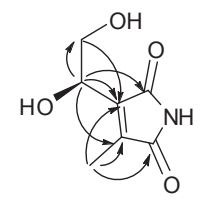

HMBC correlations of 1
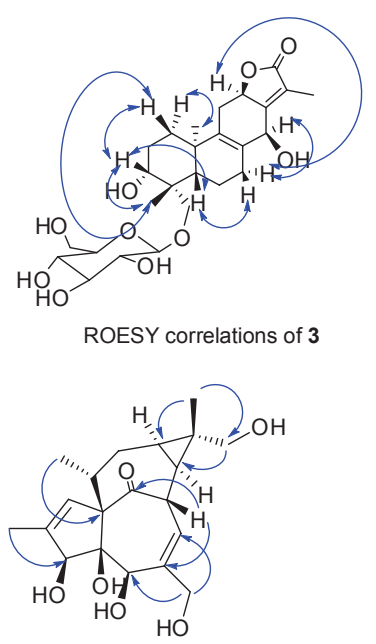

HMBC correlations of 4

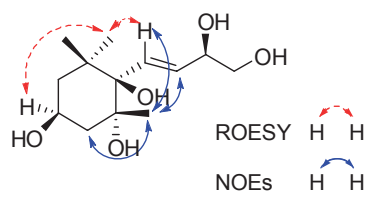

ROESY correlations and NOEs of 2

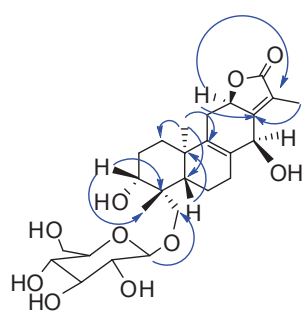

HMBC correlations of 3

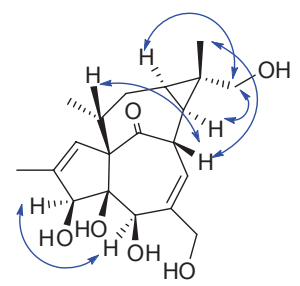

ROESY correlations of 4
Figure 2. Important HMBC and ROESYcorrelations for 1-4.

agreed with the experimental one. Thus, the absolute configuration was predicted as $R$ at C-9. The structure of $\mathbf{2}$ was therefore elucidated as $\left(1 R^{*}, 2 R^{*} 4 S^{*}\right)-1-((R, E)-3,4$-dihydroxybut-1-enyl)-2,6,6-trimethylcyclohexane-1,2,4-triol, namely euphorheliosin A.

Compound 3 had the molecular formula $\mathrm{C}_{26} \mathrm{H}_{38} \mathrm{O}_{10}$ deduced from its HRESIMS. The IR absorptions at 1738 and $1681 \mathrm{~cm}^{-1}$ in combination with the ${ }^{13} \mathrm{C}$ NMR signals at $\delta 177.4,163.7$, and 121.7 (Table 2) revealed the presence of an $\alpha, \beta$-unsaturated $\gamma$-lactone. Except for a glucosyl moiety, the ${ }^{13} \mathrm{C}$ NMR spectrum of $\mathbf{3}$ indicated an abietane diterpene characteristic of an $\alpha, \beta$-unsaturated $\gamma$-lactone. Comparing with phlogacanthoside $\mathrm{A},{ }^{13}$ the only difference for their planar structure was that 4 bears a hydroxyl at C-3, which was further supported by the HMBC responses of H-3/C-2, C-4, C-5, C-18, and C-19 (Figure 2). The relative stereochemistry of the backbone of $\mathbf{3}$ was determined by ROESY experiments: H-20/H-1 $\alpha(\delta 1.82), \mathrm{H}-3 / \mathrm{H}-18$ and $\mathrm{H}-1 \beta(\delta 1.22), \mathrm{H}-5 / \mathrm{H}-7 \beta(\delta 2.42), \mathrm{H}-7 \alpha(\delta 2.02) / \mathrm{H}-14$ and $\mathrm{H}-12$, assigning the relative configuration of the aglycone of 1 as shown. HMBC correlation of anomeric proton with C-19 confirmed the position of sugar moiety. Acid hydrolysis of $\mathbf{3}$ afforded D-glucose indicated by TLC comparison with authentic sample and its positive optical rotation. The glucose had a $\beta$-linkage with aglycone indicated by the coupling constant of anomeric proton $(J=7.6 \mathrm{~Hz}) .3$ was determined as $\left(3 R^{*}, 4 R^{*}\right.$, $\left.4 \mathrm{a} S^{*}, 7 S^{*}, 10 \mathrm{a} R^{*}, 11 \mathrm{~b} R^{*}\right)-3,7$-dihydroxy-4,8,11b-trimethyl-4$\left(\left(\left(2 R^{*}, 3 R^{*}, 4 S^{*}, 5 S^{*}, 6 R^{*}\right)-3,4,5\right.\right.$-trihydroxy-6-(hydroxymethyl) tetrahydro-2H-pyran-2-yloxy)methyl)-1,2,3,4,4a,5,6,10a,11, $11 b$,-decahydrophenanthro[3,2-b]furan- $9(7 H)$-one, namely euphorheliosin B. 
Table 2. NMR data for $\mathbf{3}^{a}$ and $\mathbf{4}^{b}$

\begin{tabular}{|c|c|c|c|c|}
\hline \multirow{2}{*}{ No } & \multicolumn{2}{|r|}{3} & \multicolumn{2}{|r|}{4} \\
\hline & ${ }^{13} \mathrm{C}$ & ${ }^{1} \mathrm{H}$ & ${ }^{13} \mathrm{C}$ & ${ }^{1} \mathrm{H}$ \\
\hline 1 & 35.5 & $\begin{array}{l}1.82(\mathrm{~m}) \\
1.22(\mathrm{~m})\end{array}$ & 129.3 & $5.8(\mathrm{~s})$ \\
\hline 2 & 28.5 & $\begin{array}{l}1.86(\mathrm{~m}) \\
1.75(\mathrm{~m})\end{array}$ & 141.3 & \\
\hline 3 & 80.1 & 3.21 (overlap) & 80.7 & $4.35(\mathrm{~s})$ \\
\hline 4 & 43.6 & & 86.0 & \\
\hline 5 & 53.2 & 1.22 (overlap) & 75.1 & $3.64(\mathrm{~s})$ \\
\hline 6 & 20.3 & $\begin{array}{l}1.92(\mathrm{~m}) \\
1.76(\mathrm{~m})\end{array}$ & 144.0 & \\
\hline 7 & 30.5 & $\begin{array}{l}2.42(\mathrm{~m}) \\
2.02(\mathrm{~m})\end{array}$ & 124.3 & $6.0(\mathrm{~d}, 5.0)$ \\
\hline 8 & 131.2 & & 44.4 & 4.32 (overlap) \\
\hline 9 & 138.2 & & 210.6 & \\
\hline 10 & 39.2 & & 74.1 & \\
\hline 11 & 33.5 & $\begin{array}{l}2.92(\mathrm{dd}, 14.7,6.7) \\
1.84 \text { (overlap) }\end{array}$ & 40.5 & $2.48(\mathrm{~m})$ \\
\hline 12 & 79.7 & $4.82(t, 8.0)$ & 31.6 & $\begin{array}{l}2.41(\mathrm{ddd}, 15.5,9.0,2.7) \\
1.74(\mathrm{dt}, 15.5,6.0)\end{array}$ \\
\hline 13 & 163.7 & & 21.4 & $0.82(\mathrm{~m})$ \\
\hline 14 & 70.8 & $4.99(\mathrm{~s})$ & 21.4 & $1.00(\mathrm{dd}, 12.0,8.8)$ \\
\hline 15 & 121.7 & & 31.3 & \\
\hline 16 & 177.4 & & 72.5 & $3.26(\mathrm{~s})$ \\
\hline 17 & 9.1 & $2.01(\mathrm{~s})$ & 11.6 & $1.18(\mathrm{~s})$ \\
\hline 18 & 23.9 & $1.24(\mathrm{~s})$ & 17.7 & $0.96(\mathrm{~d}, 7.0)$ \\
\hline 19 & 72.4 & $\begin{array}{l}4.23(\mathrm{~d}, 10.0) \\
3.59(\mathrm{~d}, 10.0)\end{array}$ & 15.5 & $1.82(\mathrm{~s})$ \\
\hline 20 & 19.2 & $1.15(\mathrm{~s})$ & 65.6 & $\begin{array}{l}4.11(\mathrm{~d}, 13.7) \\
4.04(\mathrm{~d}, 13.7)\end{array}$ \\
\hline Glc-1 & 104.9 & $4.23(\mathrm{~d}, 7.6)$ & & \\
\hline 2 & 75.1 & $3.21(\mathrm{~m})$ & & \\
\hline 3 & 77.9 & $3.29(\mathrm{~m})$ & & \\
\hline 4 & 71.6 & $3.26(\mathrm{~m})$ & & \\
\hline 5 & 78.3 & $3.37(\mathrm{~m})$ & & \\
\hline 6 & 62.7 & $\begin{array}{l}3.89(\mathrm{dd}, 11.5,1.2) \\
3.69(\mathrm{dd}, 11.5,4.8)\end{array}$ & & \\
\hline
\end{tabular}

${ }^{a}$ Measured at $100 \mathrm{MHz}$ for ${ }^{13} \mathrm{C}$ and $400 \mathrm{MHz}$ for ${ }^{1} \mathrm{H} ;{ }^{b}$ measured at 125 $\mathrm{MHz}$ for ${ }^{13} \mathrm{C}$ and $500 \mathrm{MHz}$ for ${ }^{1} \mathrm{H}$.

The molecular formula of 4 was deduced as $\mathrm{C}_{20} \mathrm{H}_{28} \mathrm{O}_{6}$ by its HRESIMS. The ${ }^{13} \mathrm{C}$ NMR spectrum revealed three methyl, three methylene, eight methin, and six quarternary carbons. The planar structure of $\mathbf{4}$ was assembled mainly by the COSY and HMBC correlations (Figure 2). Comparing to ingenol, ${ }^{14}$ the only difference was that $\mathrm{C}-16$ was oxygenated in 4 , corresponding to a downfield shift for $\mathrm{C}-16(\delta 72.5)$ The relative configuration of 4 was determined by ROESY experiments, which showed interactions of $\mathrm{H}-8 / \mathrm{H}-11$ and $\mathrm{H}-17, \mathrm{H}-16 / \mathrm{H}-13$ and $\mathrm{H}-14$, and $\mathrm{H}-3 / \mathrm{H}-5$, assigning the relative configurations of C-3, C-4, C-5, C-8, C-11, C-13, C-14, and C-15. This conclusion was identical with ingenol previously determined by X-ray diffraction. Accor- dingly, $\mathbf{4}$ was identified as 16-hydroxyingenol. Compound $\mathbf{4}$ was characterized previously by base catalysed transesterification from ingenol. ${ }^{15}$ However, it was firstly isolated as a new naturally occurring compound. Further, the ${ }^{1} \mathrm{H},{ }^{13} \mathrm{C}$ NMR data of 4 were firstly unambiguously assigned using 2D NMR techniques.

Known compounds were identified as leeaoside (5), ${ }^{16}$ roseoside II (6), ${ }^{17}$ and citroside A (7) ${ }^{18}$ by comparison of their spectroscopic data with literature values. This study provides a new insight into the chemical profiling of this plant.

\section{Experimental Section}

General procedures. Column chromatography (CC) was performed on silica gel (200 - 300 mesh; Qingdao Marine Chemical Inc., China), on $\mathrm{C}_{18}$ reverse-phase silica gel (40 - $60 \mu \mathrm{m}$; Daiso Co., Japan), MCI gel CHP 20P (75 - $150 \mu \mathrm{m}$, Tokyo, Japan) and on Sephadex LH-20 (Amersham Pharmacia, Sweden). Semi-preparative HPLC was carried out on an Agilent 1100 liquid chromatography with a Zorbax SB- $\mathrm{C}_{18}$ column $(9.4 \times 250 \mathrm{~mm}$, i.d.). UV Spectra were obtained on a Shimadzu double-beam $210 \mathrm{~A}$ spectrometer, $\lambda_{\max }$ in $\mathrm{nm}$. Optical rotations were recorded on a Horiba SEPA-300 polarimeter. IR Spectrum was determined by a Tensor 27 spectrometer, with KBr pellets; in $\mathrm{cm}^{-1}$. NMR Spectra were measured on a Bruker AV-400 or a DRX-500 spectrometer, with TMS as an internal standard. FABMS was determined on a VG Autospec-3000 spectrometer. ESIMS and HRESIMS were collected by a API QSTAR Pulsar 1 spectrometer.

Plant material. The whole plants of E. heliscopia were purchased from Kunming Juhuacun market, Kunming, Yunnan Province, China, in July 2008, and authenticated by Mr. B. Qiu. A voucher specimen (CHYX-0151) was deposited at the State Key Laboratory of Photochemistry and Plant Resources in West China, Kunming Institute of Botany, Chinese Academy of Sciences, China.

Extraction and isolation. The dried whole plant powders of E. heliscopia $(15 \mathrm{~kg})$ were extracted with $\mathrm{MeOH}$ under reflux $(3 \times 30 \mathrm{~L})$. The extracts were combined and concentrated in vacuo to yield a dark green residue, which was suspended in water followed by successive partition with petroleum ether $(3 \times 3 \mathrm{~L})$, EtOAc $(3 \times 3 \mathrm{~L})$, and $n-\mathrm{BuOH}(3 \times 3 \mathrm{~L})$. The $n$-BuOH extract $(80 \mathrm{~g})$ was separated by a silica gel $\mathrm{CC}(8.5 \times 120 \mathrm{~cm}$, 200 - 300 mesh, $1.5 \mathrm{~kg}$ ) eluted with a gradient of $\mathrm{CHCl}_{3} / \mathrm{MeOH} /$ $\mathrm{H}_{2} \mathrm{O}$ to afford four fractions (A-D). Fr. A (5.22 g) was subjected to $\mathrm{MCI}$ gel CHP 20P eluted with a gradient aqueous $\mathrm{MeOH}$ (30-60\%) to yield three subfractions (AI-AIII). Fr. AII (1.2 g) was gel filtrated on Sephadex LH-20 to obtain 4 (25 mg). Fr. AIII (800 mg) was chromatographed on Sephadex LH-20 (MeOH) to yield 2 (3 mg). Fr. B (4.3 g) was subjected to MCI gel CHP $20 \mathrm{P}$ with gradient aqueous $\mathrm{MeOH}(30-60 \%)$ as eluents to produce two portions (BI-BII). Fr. BI (1.1 g) was submitted to gel filtration on Sephadex LH-20 (MeOH) to obtain $6(18 \mathrm{mg})$. Fr. BII was purified on Sephadex LH-20 $(\mathrm{MeOH})$ to produce 7 (14 mg). Fr. C (5.8 g) was fractionated by MCI gel CHP 20P eluted with $\mathrm{MeOH} / \mathrm{H}_{2} \mathrm{O}(20-70 \%)$ to afford two portions (CICII). Fr. CI (2.0 g) was further separated on Sephadex LH-20 eluting with $\mathrm{MeOH}$ to get CI-I (50 mg), CI-II (300 mg), and 
CI-III (500 mg). Fr. CI-I was purified by semi-preparative HPLC $\left(\mathrm{MeOH} / \mathrm{H}_{2} \mathrm{O}, 40: 60\right)$ to yield $3(6 \mathrm{mg})$. Fr. CII (1.3 g) was passed through Sephadex LH-20 eluting with $\mathrm{MeOH}$ to afford CII-I (400 mg), which was subjected to $\mathrm{C}_{18}$ gel $\left(\mathrm{MeOH} / \mathrm{H}_{2} \mathrm{O}, 30 \%\right.$ ) to yield $1(15 \mathrm{mg})$. Fr. D (3.1 g) was divided into three fractions (DI-DIII) by MCI gel CHP 20P chromatography using gradient $\mathrm{MeOH} / \mathrm{H}_{2} \mathrm{O}(20-70 \%)$ as mobile phase. Fr. DII (1.1 g) was subjected to Sephadex LH-20 (MeOH) to produce DII-I (200 $\mathrm{mg}$ ), which was further purified by semi-preparative HPLC with $\mathrm{MeOH} / \mathrm{H}_{2} \mathrm{O}(30 \%)$ as mobile phase to afford 5 (4 mg).

(R)-3-(1,2-Dihydroxyethyl)-4-methyl-1 H-pyrole-2,5-dione (1): Colorless oils; $R_{f}=0.46$, silica gel $\mathrm{GF}_{254}, \mathrm{CHCl}_{3} / \mathrm{MeOH}$ $(4: 1) ;[\alpha]_{\mathrm{D}}^{24}=-21.5(c=0.3, \mathrm{MeOH}) ; \mathrm{UV}(\mathrm{MeOH}) \lambda_{\max }(\log \varepsilon)$ 222.0 (4.03), 196.8 (3.81); IR (KBr) $v_{\max } 3411,1712,1356,740$ $\mathrm{cm}^{-1} .{ }^{1} \mathrm{H}(400 \mathrm{MHz})$ and ${ }^{13} \mathrm{C}$ NMR $(100 \mathrm{MHz})$ data see Table 1. ESIMS (negative) 170 [M-H] ; HRESIMS (positive) 194.0431 $\left([\mathrm{M}+\mathrm{Na}]^{+}\right.$, calcd. for $\left.\mathrm{C}_{7} \mathrm{H}_{9} \mathrm{NO}_{4} \mathrm{Na}, 194.0429\right)$.

$\left(1 R^{*}, 2 R^{*} 4 S^{*}\right)-1-((R, E)-3,4-D i h y d r o x y b u t-1-e n y l)-2,6,6-$ trimethylcyclohexane-1,2,4-triol (2): Colorless oils; $R_{f}=0.50$, silica gel $\mathrm{GF}_{254}, \mathrm{CHCl}_{3} / \mathrm{MeOH}(4: 1) ;[\alpha]_{\mathrm{D}}^{23}=-32.8(c=0.24$, $\mathrm{MeOH})$; UV (MeOH) $\lambda_{\max }(\log \varepsilon) 202.2$ (3.63); IR (KBr) $v_{\max }$ $3406,3260,2954,2926,2871,1628,1374,1077 \mathrm{~cm}^{-1}$; ${ }^{1} \mathrm{H}(400$ $\mathrm{MHz}$ ) and ${ }^{13} \mathrm{C}$ NMR (100 MHz) data see Table 1; ESIMS (negative) $295[\mathrm{M}+\mathrm{Cl}]^{-}$; HRESIMS (negative) $295.1316\left([\mathrm{M}+\mathrm{Cl}]^{-}\right.$, calcd. for $\left.\mathrm{C}_{13} \mathrm{H}_{24} \mathrm{O}_{5} \mathrm{Cl} 295.1312\right)$.

$\left(3 R^{*}, 4 R^{*}, 4 \mathrm{a} S^{*}, 7 S^{*}, 10 \mathrm{a} R^{*}, 11 \mathrm{~b} R^{*}\right)-3,7-D i h y d r o x y-4,8,11 \mathrm{~b}-$ trimethyl-4-(( $\left(2 R^{*}, 3 R^{*}, 4 S^{*}, 5 S^{*}, 6 R^{*}\right)-3,4,5$-trihydroxy-6(hydroxymethyl)tetrahydro-2H-pyran-2-yloxy)methyl)-1,2,3, 4,4a,5,6,10a,11,11b-decahydrophenanthro [3,2-b]furan-9(7H)one (3): Colorless oils; $R_{f}=0.42$, silica gel $\mathrm{GF}_{254}, \mathrm{CHCl}_{3} / \mathrm{MeOH}$ $(4: 1) ;[\alpha]_{\mathrm{D}}^{24}=-147.4(c=0.4, \mathrm{MeOH}) ; \mathrm{UV}(\mathrm{MeOH}) \lambda_{\max }(\log \varepsilon)$ 219.2 (4.14); IR (KBr) $v_{\max } 3422,2926,1738,1681,1080 \mathrm{~cm}^{-1}$; ${ }^{1} \mathrm{H}(400 \mathrm{MHz})$ and ${ }^{13} \mathrm{C}$ NMR (100 MHz) data see Table 2; FABMS (negative) 509 [M-H]; HRESIMS (negative) 545.2136 $\left([\mathrm{M}+\mathrm{Cl}][\mathrm{M}+\mathrm{Cl}]^{-}\right.$calcd. for $\mathrm{C}_{26} \mathrm{H}_{38} \mathrm{O}_{10} \mathrm{Cl}$ 545.2153).

16-Hydroxyingenol (4): Yellowish oils; $R_{f}=0.55$, silica gel $\mathrm{GF}_{254}, \mathrm{CHCl}_{3} / \mathrm{MeOH}(5: 1) ;[\alpha]_{\mathrm{D}}^{24}=-20.0(c=0.45, \mathrm{MeOH}) ; \mathrm{UV}$ $(\mathrm{MeOH}) \lambda_{\max }(\log \varepsilon) 203.2$ (3.87); IR (KBr) $v_{\max } 3422,2874$, $1708,1015 \mathrm{~cm}^{-1} ;{ }^{1} \mathrm{H}(500 \mathrm{MHz})$ and ${ }^{13} \mathrm{C} \mathrm{NMR}(125 \mathrm{MHz})$ data see Table 2; FABMS (negative) 363 [M -H] ; HRESIMS (negative) 363.1802 ([M-H] calcd. for $\mathrm{C}_{20} \mathrm{H}_{27} \mathrm{O}_{6} 363.1807$ ).

Acid hydrolysis. A solution of $\mathbf{3}(2 \mathrm{mg})$ in $2 \mathrm{M} \mathrm{HCl}(4 \mathrm{~mL})$ was heated in a water bath at $70{ }^{\circ} \mathrm{C}$ for $6 \mathrm{~h}$. After cooling, the mixture was neutralized with $\mathrm{NaHCO}_{3}$ and extracted with $\mathrm{CHCl}_{3}$. TLC comparison with authentic sample revealed the presence of glucose in the water layer. The D-form of glucose was determined by its positive optical rotation in water $\left([\alpha]_{\mathrm{D}}^{24.0}=\right.$ $\left.+38.6\left(c=0.01, \mathrm{H}_{2} \mathrm{O}\right)\right)$ for 3 and $\left([\alpha]_{\mathrm{D}}^{24.0}=+50.4\left(c=0.53, \mathrm{H}_{2} \mathrm{O}\right)\right)$ for the authentic sample.

Acknowledgments. This work was supported by "Talent Scholarship for the Youth of Yunnan" (No. 2007PY01-48), Key Project for Drug Innovation (2008ZX09401-004) from the
Ministry of Science and Technology of China, National Natural Science Foundation of China (30770235 and 30873141), 973 Program (2009CB522304) and a grant from Chinese Academy of Sciences (YZ-06-01).

Supporting Information. NMR and MS data of 1-4 are available on line.

\section{References}

1. Shi, Q. W.; Su, X. H.; Kiyota, H. Chem. Rev. 2008, 108, 4295.

2. Hua, Y. X.; Liu, S. F.; Yang, Z. Q. Chinese Bencao; Shanghai Science and Techology Press: Shanghai, 1999; p 782.

3. Lu, Z. Q.; Guan, S. H.; Li, X. N.; Chen, G. T.; Zhang, J. Q.; Huang, H. L.; Liu, X.; Guo, D. A. J. Nat. Prod. 2008, 71, 873.

4. Lu, Z. Q.; Yang, M.; Zhang, J. Q.; Chen, G. T.; Huang, H. L.; Guan, S. H.; Ma, C.; Liu, X.; Guo, D. A. Phytochemistry 2008, 69, 812.

5. Zhang, W.; Guo, Y. W. Planta Med. 2005, 71, 283.

6. Zhang, W.; Guo, Y. W. Chem. Pharm. Bull. 2006, 54, 1037.

7. Yamamura, S.; Shizuri, Y.; Kosemura, S.; Ohtsuka, J.; Tayama, T.; Ohba, S.; Ito, M.; Saito, Y.; Terada, Y. Phtochemistry 1989, 28,3421

8. Kosemura, S.; Shizuri, Y.; Yamamura, S. Bull. Chem. Soc. Jpn. 1985, 58, 3112 .

9. Yamamura, S.; Kosemura, S.; Ohba, S.; Ito, M.; Saito, Y. Tetrahedron Lett. 1981, 22, 5315.

10. Frisch, M. J.; Trucks, G. W.; Schlegel, H. B.; Scuseria, G. E.; Robb, M. A.; Cheeseman, J. R.; Montgomery, J. A., Jr.; Vreven, T.; Kudin, K. N.; Burant, J. C.; Millam, J. M.; Iyengar, S. S.; Tomasi, J.; Barone, V.; Mennucci, B.; Cossi, M.; Scalmani, G.; Rega, N.; Petersson, G. A.; Nakatsuii, H.; Hada, M.; Ehara, M.; Toyota, K.; Fukuda, R.; Hasegawa, J.; Ishida, M.; Nakajima, T.; Honda, Y.; Kitao, O.; Nakai, H.; Klene, M.; Li, X.; Knox, J. E.; Hratchian, H. P.; Cross, J. B.; Adamo, C.; Jaramillo, J.; Gomperts, R.; Stratmann, R. E.; Yazyev, O.; Austin, A. J.; Cammi, R.; Pomelli, C.; Ochterski, J. W.; Ayala, P. Y.; Morokuma, K.; Voth, G. A.; Salvador, P.; Dannenberg, J. J.; Zakrzewski, V. G.; Dapprich, S.; Daniels, A. D.; Strain, M. C.; Farkas, O.; Malick, D. K.; Rabuck, A. D.; Raghavachari, K.; Foresman, J. B.; Ortiz, J. V.; Cui, Q.; Baboul, A. G.; Clifford, S.; Cioslowski, J.; Stefanov, B. B.; Liu, G.; Liashenko, A.; Piskorz, P.; Komaromi, I.; Martin, R. L.; Fox, D. J.; Keith, T.; Al-Laham, M. A.; Peng, C. Y.; Nanayakkara, A.; Challacombe, M.; Gill, P. M. W.; Johnson, B.; Chen, W.; Wong, M. W.; Gonzalez, C.; Pople, J. A. Gaussian 03 User's Reference, Gaussian, Inc., Pittsburgh, PA, 2003, 15106.

11. Takeda, Y.; Okada, Y.; Masuda, T. Chem. Pharm. Bull. 2000, 48, 752.

12. a) Timmons, C.; Wipf, P. J. Org. Chem. 2008, 73, 9168. b) Chen, L. X.; Zhu, H. J.; Wang, R.; Zhou, K. L.; Jing, Y. K.; Qiu, F. J. Nat. Prod. 2008, 71, 852. c) Pu, J. X.; Huang, S. X.; Ren, J.; Xiao, W. L.; Li, L. M.; Li, R. T.; Li, L. B.; Liao, T. G.; Lou, L. G.; Zhu, H. J.; Sun, H. D. J. Nat. Prod. 2007, 70, 1706. d) Hua, Y.; Ren, J.; Chen, C. X.; Zhu, H. J. Chem. Res. Chin. U. 2007, 23, 592.

13. Yuan, X. H.; Li, B. G.; Zhang, X. Y. J. Nat. Prod. 2005, 68, 86. 14. Appendino, G.; Tron, G. C.; Cravotto, G. J. Nat. Prod. 1999, $62,76$. 15. Opferkuch, H. J.; Hecker, E. Tetrahedron Lett. 1974, 3, 261.

16. Kaewkrud, W.; Otsuka, H.; Somsak, R. J. Nat. Med. 2007, 61, 449.

17. Otsuka, H.; Yao, M.; Kamada, K. Chem. Pharm. Bull. 1995, 43, 754.

18. Umehara, K.; Hattori, I.; Miyase, T. Chem. Pharm. Bull. 1988, 36, 5004. 